1447

\section{HEART RATE VARIABILITY ANALYSIS IS OF LIMITED VALUE IN ASSESSING STRESS RESPONSIVENESS DURING NEONATAL TRANSPORT}

\author{
J.-C. Bouchut ${ }^{1}$, V. Chritin ${ }^{2}$, E. Van Lancker ${ }^{2}$, \\ P.-Y. Gueugniaud ${ }^{1}$, O. Claris $^{3}$
}

'SMUR Néonatal, Hôpital Edouard Herriot, Lyon, France, ${ }^{2}$ IAV Engineering, Tannay, Switzerland,

${ }^{3}$ Réanimation Néonatale, Hôpital Mère-Enfant, Bron, France

Objective: Heart rate variability (HRV) is widely used as a marker of reactivity to a painful event in preterm and term infants. During transportation, sick neonates are highly exposed to both stationary and impulsive dynamic physical stressors. The aim of the study is to analysis HRV in assessing stress responsiveness during neonatal transport.

Method: Twenty-one newborn infants requiring transportation and nine new-born infants located in a neonatal intensive care unit were observed for the study. The ECG signal was sampled via a cardioscope and stored in a computer. All data was reviewed by an analyst to validate the QRS labeling before the analysis of the time-domain and frequency-domain indices.

Results: The median of the two groups does not differ in terms of gestational age $(2000 \mathrm{~g})$, birth weight (33 wk) or hour of life (4h). The two main diagnoses were preterm and respiratory distress syndrome.

In static condition, 120570 beat-to-beat intervals were analyzed as compared to 75068 in transport. The mean RR interval was higher in the transport group as indicated by $406 \pm 38 \mathrm{~ms}$ vs $361 \pm 25 \mathrm{~ms}$. All other indices (SDNN, RMSSD, VLF, LF, HF and LF/HF ratio) do not differ between the two groups.

The Poincaré map, where each RR interval is allocated as a functional value of the subsequent $\mathrm{RR}$ interval, does not show these differences.

Conclusions: Heart rate variability analysis is of limited value in assessing stress responsiveness during neonatal transport. Too many confusing factors may influence HRV in this situation.

1448

\section{EXPERIENCE OF HAMAD MEDICAL CORPORATION (HMC) DOHA QATAR.IN THE OVERSEAS TRANSFER OF SICK CHILDREN USING COMMERCIAL, NON-MEDICALLY DICTATED FIXED-WING AIRCRAFTS}

\author{
O.Y. Al Glbali
}

Pediatrics Pediatric Critical Care Medicine, Hamad Medical Corporaion, Doha, Qatar

The air transportation of sick patients can be carried via helicopters or fixed winged aircrafts. However, the latter has the advantage of transferring very sick patients over longer distances. Also it is quitter, faster, and more spacious.

The objective of this research is to study the experience and the outcome of Hamad Medical Corporation (HMC) Doha Qatar.in the overseas transfer of sick children using commercial, nonmedically dictated fixed-wing aircrafts.

Methods: All patients data collected from the overseas medical office at National Health Authority, Qatar. The study was approved by the ethical committee of HMC research center. During the period Jan 1999 and March 2008 among all patients who transported by the above mentioned mean 459 were of pediatric age group (below 14 years of age according to our definition). We reviewed 247 air trips. Demographic data, indications of transportation, logistic support, equipments, team composition, and adverse events occurred during transportation were evaluated.

Results: Average duration of transportation per trip was 12 hours, and the average flight duration was 8 hours. 21 children were critically ill (define as those who were on mechanical ventilation or intravenous inotropic support during transportation).

All patients arrived to the overseas distention without adverse event, only one child developed bradycardia resuscitated on arrival to distenation and expiered after one hour.

Conclusion: The experience of Hamad Medical Corporation (HMC) Qatar showed overseas transfer of sick children using commercial, non-medically dictated fixed-wing aircrafts, to be safe if under taken with full preparation, good communication, and logistic support. 